\title{
Avaliação da disciplina Formação Didático-Pedagógica em Saúde: a ótica dos pós-graduandos
}

\section{Evaluation of the discipline Didactic-Pedagogical Formation in Health: the graduate student's perspective}

\section{Evaluación de la Disciplina Formación Didáctico- Pedagógica en Salud: la óptica de los alumnos de posgrado}

Irani Ferreira Gerab, doutora em Ciências Biológicas (Biologia Molecular) pela Universidade Federal de São Paulo (Unifesp), professora adjunta da Universidade Federal de São Paulo e Diretora do Centro de Desenvolvimento do Ensino Superior em Saúde (Cedess). E-mail: irani. silva@unifesp.br.

Sylvia Helena Batista, doutora em Psicologia da Educação pela Pontifícia Universidade Católica de São Paulo (PUC-SP) e coordenadora do Programa de Mestrado Ensino em Ciências da Saúde da Universidade Federal de São Paulo (Unifesp). E-mail: sylvia.batista@unifesp.br.

Maria Cecilia Sonzogno, doutora em Psicologia da Educação pela Pontifícia Universidade Católica de São Paulo (PUC-SP) e coordenadora do Curso de Especialização Educação em Saúde, do Centro de Desenvolvimento do Ensino Superior em Saúde (Cedess). E-mail: mcsonzogno@uol.com.br.

Claudinéa Guedes Yamashiro, mestre em Ensino em Ciências da Saúde pela Universidade Federal de São Paulo (Unifesp) e professora do Instituto Brasileiro de Acupuntura e Homeopatia (Ibraho). E-mail: clauyamashiro@gmail.com.

Fábio Gerab, doutor em Física Aplicada pela Universidade de São Paulo (USP), professor titular e chefe do Departamento de Matemática do Centro Universitário da Fundação Educacional Inaciana (FEI). E-mail: prifgerab@fei.edu.br. 
Lidia Ruiz-Moreno, doutora em Biologia pela Universidad Nacional de Córdoba, Argentina, e vice-coordenadora do Programa de Mestrado Ensino em Ciências da Saúde (Cedess/Instituto Saúde e Sociedade), da Universidade Federal de São Paulo (Unifesp). E-mail: lidia.ruiz@unifesp.br.

\section{Resumo}

Na Universidade Federal de São Paulo, a disciplina Formação Didático-Pedagógica em Saúde (FDPS) é oferecida pelo Centro de Desenvolvimento do Ensino Superior em Saúde (Cedess/Unifesp) aos alunos dos programas de pós-graduação stricto sensu, desde 1996. Objetiva este trabalho analisar limites e possibilidades dessa disciplina a partir da ótica dos pós-graduandos. A metodologia utilizada foi a análise quanti-qualitativa de questionários. Os dados indicaram satisfação dos alunos e estímulo à reflexão, à participação e à troca de experiências. Inicialmente, eles manifestam expectativas sobre a dimensão técnica da docência e, gradativamente, se sensibilizam sobre as suas dimensões políticas e sociais. A disciplina propicia um espaço de reflexão sobre o papel do professor do ensino superior, considerando o contexto social e as políticas públicas de educação e de saúde no País.

Palavras-chave: Docência. Saúde. Desenvolvimento Docente. PósGraduação. Ensino Superior.

\section{Abstract}

At the Universidade Federal de São Paulo, the discipline of Didactic-Pedagogical Formation in Health has been offered since 1996 by the Center for Development of Higher Education in Health (Cedess/ Unifesp) for students of the graduate program. The objective of this research is to analyze limits and possibilities of this discipline from the graduate student's perspective. The methodology used involved the quantitative and qualitative analysis of questionnaires. The obtained data indicated student satisfaction and encouragement for reflection, participation and exchange of experiences. Initially, students revealed their expectations regarding the technical dimension of teaching, but 
they gradually became aware of its political and social dimensions as well. This discipline provides an opportunity for reflection on the teacher's role in higher education, considering the country's social context and its public policies for education and health.

Keywords: Teaching. Health.Teaching Development.Graduate Study. Higher Education.

\section{Resumen}

En la Universidad Federal de São Paulo, la Disciplina Formación Didáctico-Pedagógica en Salud (FDPS) es ofrecida por el Centro de Desenvolvimento do Ensino Superior em Saúde (Cedess/Unifesp) a los alumnos los programas de posgrado stricto sensu, desde 1996. Este estudio tiene como objetivo analizar límites y posibilidades de esta disciplina desde de la óptica de sus alumnos. Se utilizó como metodología el análisis cuanti-cualitativo de cuestionarios. Los datos indicaron satisfacción de los alumnos, estímulo a la reflexión, participación e intercambio de experiencias. Inicialmente manifiestan expectativas sobre la dimensión técnica de la docencia e, gradualmente se sensibilizan por sus dimensiones políticas y sociales. La disciplina proporciona un espacio de reflexión sobre el papel del profesor de la educación superior considerando el contexto social y las políticas públicas de educación y salud en el país.

Palabras-clave: Docencia. Salud. Desarrollo Docente. Posgrado. Educación Superior.

\section{Introdução}

O importante é que nos ouçamos uns aos outros.

(SARAMAGO, 1995, p. 57)

A formação docente tem constituído tema relevante e desafiador, objeto de pesquisas, produções científicas, encontros e congressos. Desafio para docentes, formadores e gestores das instituições de 
ensino superior no sentido de proporem caminhos que contribuam para a construção de uma cultura que assuma a docência como profissão (ROLDÃO, 2007).

Ao situarmos a docência na área da saúde, encontramos algumas raízes históricas na preocupação com o preparo do professor para desenvolver suas atividades de ensino no âmbito da graduação em Medicina. O Parecer n 576/70, do Conselho Federal de Educação (BRASIL, 1970), que estabelece normas complementares para o credenciamento dos cursos de pós-graduação na área médica, determina, em seu art. 5 que os currículos desses cursos deverão incluir as disciplinas Pedagogia Médica e Didática Especial. Também a Resolução $n^{\circ}$ 11/77, em seu art. $8^{\circ}$ (BRASIL, 1977), recomenda que os cursos stricto sensu abranjam as mencionadas disciplinas.

A nova Lei de Diretrizes e Bases da Educação (Lei n 9.394, de 1996) situa os cursos de mestrado e doutorado como espaços privilegiados para a formação do professor do ensino superior, destacando em seu art. 66: “[...] a preparação para o exercício do magistério superior farse-á em nível de pós-graduação, prioritariamente em programas de mestrado e doutorado" (BRASIL, 1996).

É assim que, em meio a expectativas legais, institucionais e acadêmicas, a experiência com as disciplinas Pedagogia Médica e Didática Especial foi se configurando na Universidade Federal de São Paulo. A partir de 1996, essas disciplinas passaram a ser trabalhadas de maneira integrada na instituição, configurando a disciplina Formação Didático-Pedagógica em Saúde - FDPS, desenvolvida pelo Centro de Desenvolvimento do Ensino Superior em Saúde, da Unifesp (BATISTA, 1997; BATISTA; SILVA, 1998).

Nesse contexto, o presente artigo tem como objetivo discutir criticamente as avaliações que os pós-graduandos fazem da disciplina Formação Didático-Pedagógica em Saúde, modalidade presencial. 


\section{Descrevendo um itinerário de formação: dos sujeitos à dinâmica dos encontros}

A disciplina Formação Didático-Pedagógica em Saúde compreende uma carga horária de 60 horas (sendo 30 horas presenciais, distribuídas em dez encontros de três horas) e tem como cenário singular para sua realização o Laboratório de Práticas de Ensino, especialmente montado para que os pós-graduandos possam vivenciar momentos formativos que articulem reflexões e debates sobre as dimensões da docência com a utilização e a análise crítica de diferentes recursos de ensino e aprendizagem.

As turmas têm de 30 a 35 alunos, considerando nossa crença de que a formação docente deve privilegiar interações de troca, favorecendo a proximidade, o diálogo e o trabalho coletivo.

A proposta educativa envolve docentes e discentes de origens diferenciadas no que se refere a seus cursos de graduação, inserções profissionais e envolvimento com a graduação em saúde. Importante destacar que aproximadamente $25 \%$ dos mestrandos e doutorandos já estão inseridos na atividade acadêmica, desenvolvendo a docência universitária. Para esses pós-graduandos, a disciplina parece significar um espaço de reflexão e discussão da própria prática, trazendo para a sala de aula importantes contribuições de seus cotidianos como professores.

A pluralidade, a diversidade e a multiplicidade caracterizam, assim, professores e alunos que compartilham o mesmo espaço de formação docente. Nesse cenário, desenvolve-se uma dinâmica constituída por três momentos: a discussão e a reflexão sobre temáticas relativas à docência em saúde, a prática docente e o planejamento em educação e saúde.

A discussão e a reflexão sobre temáticas relativas à docência em saúde privilegiam o pensar coletivo a partir de textos e experiências em torno de núcleos que problematizam o ensinar e o aprender no campo das Ciências da Saúde. Esses núcleos abrangem o processo 
de formação em saúde; o planejamento de ensino; os processos de ensino, aprendizagem e avaliação: concepções, instrumentos e funções no processo educativo; o currículo e os movimentos de transformação do ensino em ciências da saúde; as metodologias de ensino: técnicas e recursos didáticos; as inovações educacionais, o caso das metodologias ativas; a leitura como instrumento para o trabalho docente e a dimensão ética na formação em saúde.

Esses momentos de problematização, desenvolvidos com base em textos e/ou situações-problemas, oportunizam aos pósgraduandos que se apropriem das concepções sobre o que é ser professor universitário em saúde. Instigante perceber que os valores, crenças e saberes são partilhados no sentido de favorecerem a troca de conhecimentos e a busca pelo aprofundamento. Assim, temos investido em estratégias metodológicas que possibilitem a expressão dos alunos: preleções dialogadas, dinâmicas de grupo, cartas, relatos de experiências, desenhos e mapas conceituais, entre outras (BATISTA, 2002; SEIFFERT; BATISTA, 2005; RUIZ-MORENO; PITTAMIGLIO; FURUSATO, 2008; RUIZMORENO; SONZOGNO, 2011).

Em um segundo momento, é privilegiada a prática docente, que se constitui na vivência, pelos pós-graduandos, de diferentes estratégias didáticas (aula expositiva, preleção dialogada, aula demonstrativa, mesaredonda) e na análise dessas vivências, tendo como objetivo central uma reflexão sobre o lugar das estratégias de ensino e dos recursos didáticos na construção de conhecimento nos diferentes cenários (sala de aula, laboratório, enfermaria, unidade básica de saúde, escola).

Busca-se superar um enfoque meramente prescritivo - como se faz -, para se assumir uma perspectiva que articula técnica, reflexão e crítica. Nesse sentido, estamos procurando estabelecer, após a vivência, uma autoavaliação do pós-graduando sobre como se sentiu coordenando uma dada estratégia e uma heteroavaliação, com o professor e o grupo analisando o que foi vivenciado. Durante a discussão, buscamos problematizar os pressupostos pedagógicos implícitos na escolha e na seleção das metodologias de ensino.

O planejamento de ensino compreende um processo de construção coletiva de proposta de ação educativa em saúde. Realizado 
em pequenos grupos no decorrer da disciplina e com acompanhamento docente, o planejar envolve a explicitação das intencionalidades, favorecendo não apenas aprendizagens relativas ao ato de planejar, mas também uma reflexão sobre os compromissos sociais do docente na área da saúde (BATISTA; BATISTA, 2004).

Os planejamentos educacionais são apresentados ao final da disciplina, estabelecendo-se uma rica e diversificada rede de planos, intencionalidades e escolhas discutidas, sendo possivel apreender o impacto dessa experiência no trabalho em grupo, aprender a lidar com as diferenças, a negociar e a construir consensos.

Estes três momentos caracterizam a dinâmica dos encontros: primeiro, desenvolve-se uma prática docente que traduz um dado planejamento; depois, transita-se permanentemente por entre os conteúdos sistematizados da ciência educacional, as representações dos sujeitos e os condicionantes da área da saúde como prática social e historicamente situada; por fim, lida-se com a diversidade profissional, exigindo a contextualização das profissões e de seus processos de formação, ensino e aprendizagem, além da construção de práticas interdisciplinares.

No sentido de conhecer a perspectiva dos pós-graduandos sobre a experiência vivenciada, foi aplicado um questionário, a ser preenchido de forma anônima e voluntária, no último encontro da disciplina.

\section{0 percurso metodológico do estudo}

Foram analisados quanti-qualitativamente 251 questionários relativos à avaliação das oito turmas da disciplina FDPS. Esse instrumento é composto por 30 assertivas em que os pós-graduandos devem manifestar o grau de concordância por meio de uma escala de Likert com grau de intensidade crescente de 1 a 5 (GRESSLER, 2003). Além disso, existe um espaço aberto para eventuais comentários que o aluno julgue importante fazer. Os dados relativos à escala de Likert foram analisados estatisticamente por análise multivariada. Os comentários foram submetidos à análise temática (MINAYO, 2004). 


\section{Análise multivariada}

Os resultados provenientes da aplicação de questionários com assertivas fechadas com um número de respondentes substancialmente maior que o de assertivas (ao menos cinco vezes maior) tornam possível a sua análise estatística por intermédio de uma abordagem multivariada (HAIR, 2005). Em particular, para questionários aplicados em escala de Likert, é possível aplicar testes de confiabilidade na amostra (PEREIRA, 2004), conjugados à análise de componentes principais, não só para interpretar os resultados dos questionários, mas também para validálos como instrumento de medida em si.

Essa abordagem tem se mostrado eficaz na identificação de relações entre grupos de assertivas em questionários de elevado grau de complexidade (PEREIRA, 2004). Quando duas ou mais variáveis (assertivas) envolvidas na análise não são completamente independentes, elas podem ser agrupadas por meio da criação de uma nova variável, a partir das antigas, chamada componente principal. Nesse processo, pode-se também identificar - e excluir da análise - assertivas que não foram capazes de contribuir para a interpretação do questionário como um todo, seja por não terem sido interpretadas de forma homogênea pelos respondentes, seja por, implicitamente, conterem em sua construção mais de um questionamento. Esse conjunto de procedimentos reduz a complexidade do problema em estudo, sem acarretar perda significativa de informação. Simultaneamente, ele evidencia as relações entre as variáveis originais.

Neste trabalho, a finalidade da aplicação da análise de componentes principais foi reduzir a complexidade do questionário aplicado, identificando as distintas dimensões (ou constructos) por ele mensuradas por intermédio do agrupamento de conjuntos de assertivas nos componentes principais, possibilitando uma melhor interpretação das respostas obtidas.

A validação do questionário como ferramenta efetiva de avaliação dos constructos identificados pôde ser feita separando-se somente as assertivas associadas a cada componente principal e aplicando- 
se novas análises de confiabilidade e de componentes principais a cada um dos subconjuntos de assertivas. Nessa etapa da análise, confirma-se se as assertivas associadas a um dado componente principal relacionam-se a um único constructo e se todas elas realmente contribuem positivamente para a sua mensuração. Essa abordagem possibilita a criação de indicadores quantitativos válidos para cada um dos constructos identificados.

A Figura 1, na qual foram calculadas as médias e os desvios padrões dos indicadores obtidos, resume os procedimentos adotados nesse processo:

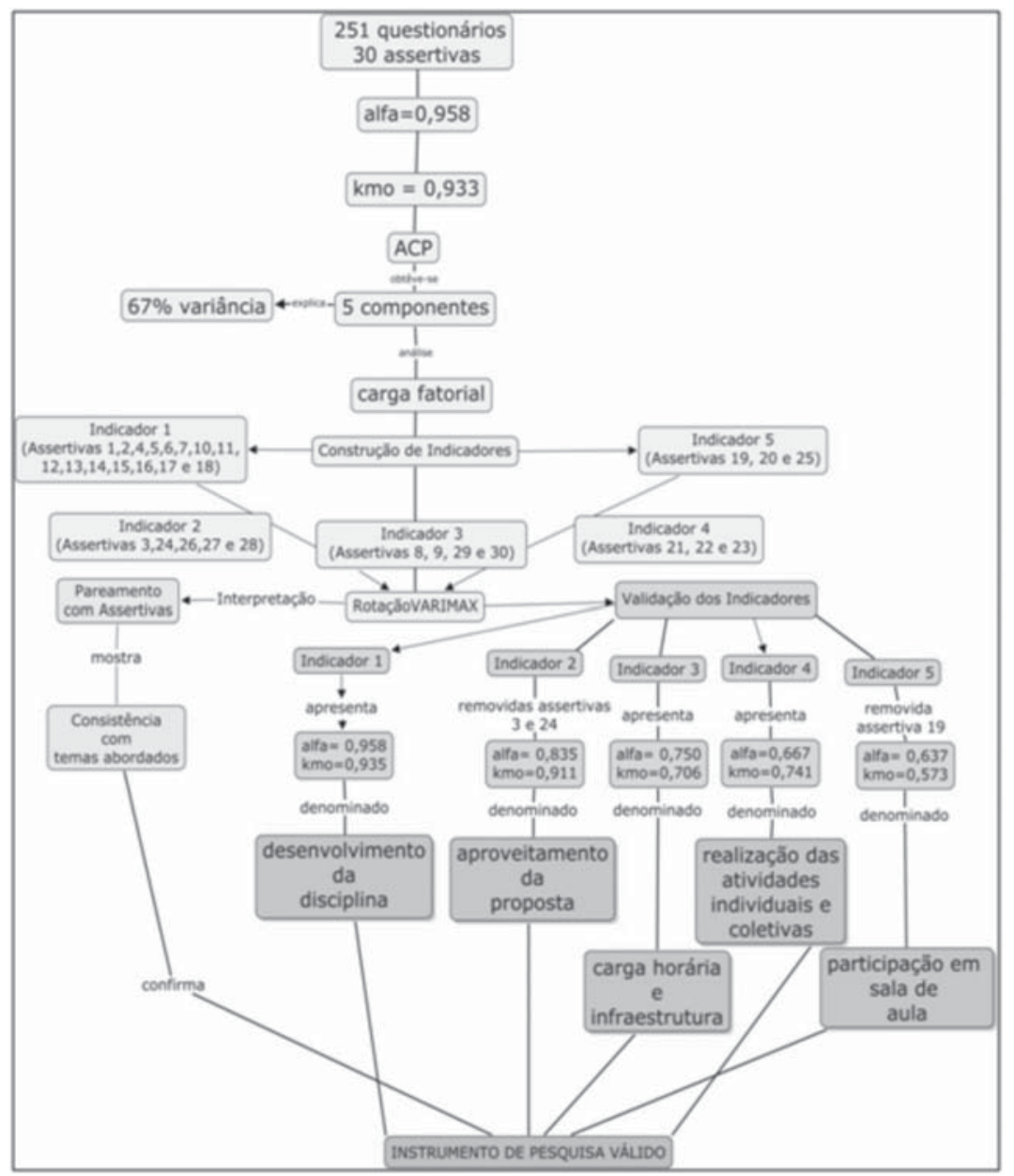

Figura 1. Fluxograma das etapas de validação do instrumento de avaliação da disciplina FDPS 
Na Tabela 1, estão apresentadas as assertivas associadas a cada um dos constructos validados.

Tabela 1. Assertivas associadas a cada um dos indicadores validados

\section{Desenvolvimento da disciplina}

1 A proposta da disciplina mostra-se coerente em seus objetivos, atividades e planejamento.

2 Os objetivos, conteúdos, metodologias do ensino e processo de avaliação da disciplina foram apresentados e discutidos com os alunos.

4 As situações de ensino e aprendizagem utilizadas estimularam a participação e a análise reflexiva e crítica dos alunos.

5 As atividades desenvolvidas propiciaram trocas de experiências entre os alunos e o professor, favorecendo o trabalho em equipe.

\begin{tabular}{c|l}
\hline 6 & $\begin{array}{l}\text { As técnicas e procedimentos de ensino foram diversificados, atendendo } \\
\text { a proposta metodológica da disciplina. }\end{array}$ \\
\hline 7 & A articulação entre teoria e prática mostrou-se adequada. \\
\hline 10 & $\begin{array}{l}\text { O processo de avaliação de aprendizagem propiciou um acompanhamento } \\
\text { contínuo dos alunos. }\end{array}$ \\
\hline 11 & $\begin{array}{l}\text { A bibliografia indicada é adequada à proposta de desenvolvimento da } \\
\text { disciplina. }\end{array}$ \\
\hline 12 & $\begin{array}{l}\text { A bibliografia contribuiu para o aprofundamento dos conteúdos } \\
\text { abordados na disciplina. }\end{array}$ \\
\hline 13 & $\begin{array}{l}\text { O professor esclareceu o significado e a importância da disciplina para } \\
\text { a formação do profissional da saúde. }\end{array}$ \\
\hline 14 & $\begin{array}{l}\text { O professor desenvolveu aulas com competência (conteúdo específico } \\
\text { e didática), favorecendo o aprofundamento dos conceitos trabalhados. }\end{array}$ \\
\hline 15 & $\begin{array}{l}\text { O professor empregou técnicas de ensino diversificadas, estimulando } \\
\text { a participação ativa do aluno. }\end{array}$ \\
\hline 16 & O professor favoreceu uma relação cordial e de trocas com os alunos. \\
\hline 17 & $\begin{array}{l}\text { O professor teve disponibilidade para esclarecer dúvidas dos alunos, } \\
\text { contribuindo para o aprofundamento de conteúdos. }\end{array}$ \\
\hline 18 & $\begin{array}{l}\text { O professor adotou práticas de avaliação que permitiram o } \\
\text { acompanhamento contínuo da aprendizagem dos alunos e do } \\
\text { desenvolvimento da disciplina. }\end{array}$ \\
\hline
\end{tabular}

\section{Aproveitamento da proposta}

26 Percebi mudanças em minha maneira de refletir sobre os problemas do ensino em saúde.

27 Julgo-me mais capacitado(a) para resolver questões de ensino do que antes de iniciar o curso.

Considero que tive um bom aproveitamento na disciplina, conseguindo

28 compreender melhor minhas possibilidades de inserção no ensino em saúde. 


\section{Carga horária e infraestrutura}

\begin{tabular}{c|l}
\hline 8 & $\begin{array}{l}\text { A carga horária das atividades é compatível com a natureza dos } \\
\text { conteúdos e das atividades propostas. }\end{array}$ \\
\hline 9 & $\begin{array}{l}\text { O tempo necessário para a realização de tarefas/estudos solicitados } \\
\text { para os períodos extraclasse foi compatível com as suas possibilidades } \\
\text { de dedicação à disciplina. }\end{array}$ \\
\hline 29 & As atividades da disciplina estão sendo realizadas em local adequado. \\
\hline 30 & $\begin{array}{l}\text { Os materiais e equipamentos necessários estão disponíveis para o bom } \\
\text { desenvolvimento das atividades programadas. }\end{array}$ \\
\hline Realização de atividades individuais e coletivas \\
\hline 21 & $\begin{array}{l}\text { Realizei as tarefas/estudos individuais e em grupos propostas na } \\
\text { disciplina. }\end{array}$ \\
\hline 22 & $\begin{array}{l}\text { Na atividade de planejamento, participei ativamente, contribuindo com } \\
\text { ideias, textos e propostas para que o grupo conseguisse construir o } \\
\text { plano de ensino. }\end{array}$ \\
\hline Realização de atividades individuais e coletivas \\
\hline 23 & Fui cordial no relacionamento com os colegas e professor. \\
\hline Participação em sala de aula \\
\hline 20 & Participei ativamente das discussões e atividades propostas. \\
\hline 25 & $\begin{array}{l}\text { Mostrei-me disponivel para realizar alguma das estratégias de ensino } \\
\text { propostas no desenvolvimento da disciplina. }\end{array}$ \\
\hline
\end{tabular}

\section{Análise temática}

A análise das questões abertas correspondentes a cada eixo foi realizada por meio da utilização de 120 questionários, uma vez que nem todos os alunos redigiram respostas no espaço destinado a esse fim. Esses dados foram submetidos a uma análise temática de acordo com os seguintes eixos: Organização da disciplina, Infraestrutura, Desempenho docente e Autoavaliação (MINAYO, 2004).

\section{Resultados e discussão}

No Quadro 1, são apresentados os resultados médios obtidos para cada constructo identificado no questionário. 
Quadro 1. Média e desvio padrão obtidos para cada constructo identificado no instrumento de avaliação da disciplina FDPS

\begin{tabular}{c|c|c|c|c|c}
\hline Indicador & $\begin{array}{c}\text { Práticas } \\
\text { de } \\
\text { ensino }\end{array}$ & $\begin{array}{c}\text { Aproveitamento } \\
\text { da proposta }\end{array}$ & Infraestrutura & $\begin{array}{c}\text { Realização } \\
\text { de } \\
\text { atividades } \\
\text { individuais } \\
\text { e coletivas }\end{array}$ & $\begin{array}{c}\text { Participação } \\
\text { em sala de } \\
\text { aula }\end{array}$ \\
\hline Média & 4,349 & 4,280 & 3,912 & 4,707 & 4,143 \\
\hline $\begin{array}{c}\text { Desvio } \\
\text { Padrão }\end{array}$ & 0,741 & 0,867 & 0,893 & 0,469 & 0,883 \\
\hline
\end{tabular}

Nota-se uma avaliação positiva dos indicadores obtidos, principalmente quanto à realização das atividades individuais e coletivas, evidenciando que a disciplina motiva os alunos a uma participação ativa.

Quanto à infraestrutura, os dados mostram insatisfação por parte dos pós-graduandos. A precariedade do espaço físico evidencia os desafios que uma instituição pública enfrenta, tanto no que se refere às condições de espaço para as atividades desenvolvidas quanto aos equipamentos disponiveis para a realização das atividades.

A avaliação da proposta pedagógica evidenciou satisfação entre os pós-graduandos, como se observa no resultado satisfatório do indicador "Práticas de ensino" constante do Quadro 1 e nos comentários realizados no instrumento de coleta de dados, especialmente os que se referem às reflexões propiciadas pela integração dos aspectos didáticopedagógicos:

$\checkmark \quad$ "O conteúdo pedagógico teórico da disciplina propiciou bastante reflexão a respeito da prática em sala de aula, assim como os exercícios didáticos";

$\checkmark$ "Aproveitei o curso de modo satisfatório, participando das atividades de maneira crítica";

$\checkmark$ "Espero agora persistir avaliando novas possibilidades para otimização de minha prática didática”.

Esses dados corroboram achados que situam a construção de um novo docente em saúde como um processo que demanda meios de formação os quais assumam a prática como eixo estruturante, privilegiando o diálogo, a leitura crítica, os saberes da experiência em 
articulação com os saberes científicos, os significados e a problematização das situações de ensino e aprendizagem (BATISTA; BATISTA, 2004).

O entendimento da docência como profissão por parte dos pósgraduandos é importante, uma vez que, com frequência, a atividade docente é vista como secundária, sendo a competência técnicocientífica o critério definidor de competência docente (FEUERWERKER, 1998). Zabalza (2004) define essa perspectiva como a concepção não profissional da formação docente, pois os professores consideram que ensinar se aprende ensinando, ou seja, reproduzem de maneira acrítica e intuitiva modelos aprendidos previamente na sua experiência educacional. Em uma visão mais ampliada, essa prática é reconhecida como natural na escola, transformando-se em um conceito espontâneo e generalizado sobre o que seja ensinar. 0 autor defende uma concepção profissional da formação docente que considera o ensino uma tarefa complexa e um desafio social, com exigências e habilidades que podem ser apreendidas por meio de um processo formativo.

No âmbito das limitações da proposta educativa desenvolvida no Cedess, um número significativo de alunos se referiu à necessidade de ampliar o treino de práticas de ensino desenvolvidas por eles que incluam técnicas de falar em público e de obter maior domínio no uso de recursos didáticos de apresentação de conteúdos.

Os pós-graduandos, inicialmente, manifestam expectativas quanto à dimensão técnica da docência universitária e, gradativamente, se sensibilizam sobre as dimensões políticas e o comprometimento social do professor universitário. As reflexões sobre os aportes de Paulo Freire durante os encontros ampliaram as concepções sobre o processo ensino-aprendizagem, incluindo a perspectiva transformadora da realidade, como ficou evidenciado no seguinte comentário de um dos alunos: "os temas e estratégias me levaram a refletir sobre o processo ensino-aprendizagem e de como posso, tanto individualmente quanto socialmente/coletivamente, me comportar e agir como agente de transformação".

Os participantes parecem avançar na compreensão de que o preparo para a função docente em saúde não significa apenas a 
instrumentalização técnica, mas, fundamentalmente, uma reflexão crítica dessa prática e da realidade em que ela se realiza (BATISTA; BATISTA, 2004; FREITAS; SEIFFERT, 2007).

Nesse sentido, refletir sobre a docência em saúde ganha uma ampliação significativa quando se considera que o exercício profissional na área traz implícita a materialização de um ato educativo: formar-se e formar o outro emergem como práticas sociais permanentes dos diferentes profissionais que transitam no campo da saúde.

Os dados deste estudo corroboram os encontrados por Batista (1997) em sua pesquisa-ação sobre a disciplina Formação DidáticoPedagógica em Saúde, na qual o autor constatou que a proposta educativa propicia:

$\checkmark$ A ampliação do conceito de função docente em saúde, de uma posição tecnicista para uma visão mais ética e humanística do relacionamento professor-aluno;

$\checkmark \quad$ O estabelecimento de uma série de atributos para o professor de Medicina como subsídio para mudança de práticas;

$\checkmark$ A opção por abordagens de ensino mais interativas, por intermédio de múltiplos meios, em substituição às aulas expositivas tradicionais; e

$\checkmark$ A construção da competência para planejar uma atividade educativa em saúde, bem como a percepção do significado desse planejamento para um processo ensinoaprendizagem mais criativo e crítico.

Também Ruiz-Moreno, Sonzogno, Batista e Batista (2007), ao analisarem mapas conceituais produzidos pelos alunos, encontram resultados semelhantes, havendo uma maior ênfase na dimensão sócio-política da docência universitária em saúde, além de um grande destaque às dimensões éticas e interativas nas relações professor / aluno. Comenta a autora ainda que a percepção da leitura como um instrumento para o trabalho do professor e as inovações metodológicas são destacadas como eixos importantes na avaliação dos pósgraduandos. 
Uma segunda dimensão identificada nos comentários dos alunos compreende o desempenho docente em seus aspectos relacionais, didático-pedagógicos, éticos e de apropriação dos saberes relativos ao campo da docência universitária em saúde. A atuação docente foi avaliada positivamente pelos pós-graduandos. Entre os atributos valorizados, estão a competência didática e cognitiva e a atitude disponivel para acompanhamento dos alunos, esclarecimento de dúvidas e integração teórico-prática em um clima emocional adequado.

No processo de formação de professores, é preciso integrar a diversidade dos saberes requeridos para o desempenho da função docente, o que diz respeito ao modo como ele se apropria do "ser professor" em sua vida, quais sejam: saberes específicos das áreas de conhecimento, saberes pedagógicos e saberes da experiência do professor (TARDIF, 2000).

O professor constitui um dos sujeitos nucleares para a transformação do processo ensino-aprendizagem em saúde, o que demanda que sejam colocadas em discussão as concepções que têm orientado as práticas pedagógicas (BATISTA; BATISTA, 2002). A docência em saúde apresenta especificidades também no que se refere à intermediação de um outro sujeito na relação professor-aluno, incluindo um paciente/comunidade que é sujeito/objeto do ensino e do cuidado (BATISTA, 1997; BATISTA; RIBEIRO, 2000). Nesse sentido, o trabalho em pequeno grupo para elaboração do planejamento educacional favorece uma aproximação bastante significativa para propostas que se comprometam com uma formação crítico-dialógica. É possível ouvir, falar, argumentar, trocar, em uma perspectiva de construção de redes de saberes e experiências que alimentem um processo permanente de ação-reflexão-ação.

Nóvoa ressalta:

Hoje, a complexidade do trabalho escolar reclama um aprofundamento das equipas pedagógicas. A competência colectiva é mais do que o somatório das competências individuais. Estamos a falar da necessidade de um tecido profissional enriquecido, da necessidade de integrar na cultura docente um conjunto de modos colectivos de produção e de regulação do trabalho (2009, p. 40, grifo do autor). 
Quanto à autoavaliação, os pós-graduandos consideram sua participação razoável, mas com limitada dedicação à leitura da bibliografia recomendada, devido à falta de tempo disponível. As reflexões propiciadas na autoavaliação expressam que, apesar do "pouco interesse inicial", a motivação para aprimorar sua prática docente e participar de processos de educação permanente aumentou durante os encontros: "Foi um curso muito interessante, pois me estimulou a repensar a minha prática no ensino, a buscar mais embasamento teórico de como ser professor; a responsabilidade de quem ensina e como isso se dá têm muito mais impacto do que eu imaginava”, disse um deles.

Os alunos parecem compreender que a formação docente como processo não se restringe a territórios disciplinares, pois se inscreve em um contorno de permanente (re)construção de saberes e fazeres. Ainda assim, constituir disciplinas que privilegiem essa formação pode representar um fecundo caminho de debate, análise e aprendizagem da docência.

\section{Considerações Finais}

Os pós-graduandos, inicialmente, manifestam expectativas quanto à dimensão técnica da docência universitária e, gradativamente, se sensibilizam com as dimensões políticas e com o comprometimento social do professor universitário.

A contribuição da disciplina no processo de formação docente é um aspecto que supera as expectativas iniciais dos alunos e os estimula a continuar no processo de educação permanente. Os limites colocados indicam a necessidade não somente da adequação do espaço físico (considerando o número de participantes dos grupos), mas também de uma inserção crítica e uma maior exposição dos alunos às atividades de exercício docente, problematizando os encontros com os estudantes.

As práticas de formação docente em saúde comprometidas com a interdisciplinaridade, a ética, a crítica e o diálogo têm de constituir situações de troca, de interlocução entre os saberes da experiência e os 
saberes científicos e de negociação de significados. O futuro professor dificilmente empreenderá uma docência que assuma o aluno como sujeito de sua aprendizagem se não estiver envolvido em contextos de partilha, de debates de ideias, de reconhecimento dos próprios limites e das possibilidades.

Ressignificar os espaços disciplinares nos cursos de mestrado e de doutorado emerge como processo importante na ampliação dos espaços que assumam a análise da docência como um eixo prioritário, investindo em uma articulação ensino-pesquisa, na formação do professor universitário em saúde.

Esse movimento implica reconhecer e assumir que as propostas de formação têm significativa dimensão institucional: inserir os projetos nos planos das instituições representa uma condição importante para a assunção da docência como profissão. Nessa direção, não se trata de deixar para o professor a responsabilidade de planejar e organizar espaços formativos, mas de abrigar políticas institucionais de valorização da formação docente.

Essa formação situa-se como um processo permanente no qual momentos de reflexão podem contribuir para teorizar a própria prática, desenvolvendo referenciais teórico-metodológicos que viabilizem uma análise crítica, comprometida e consequente na transformação do ensino em ciências da saúde.

Recebido em 19/01/2013

Aprovado em 22/04/2013 


\section{Referências}

BATISTA, N. A.; BATISTA, S. H. S. S. A formação do professor universitário em saúde: desafios e perspectivas. In: FAZENDA, I.; SEVERINO, A. J. Formação docente: rupturas e possibilidades. Campinas: Papirus, 2002.

A função docente em medicina e a formação/educação permanente do professor. Revista Brasileira de Educação Médica, Rio de Janeiro, v. 22, n. 2/3, 1998.

(Orgs.). Docência em saúde: temas e experiências. 1. ed. São Paulo: Senac São Paulo, 2004.

BATISTA, N. A. Conhecimento, experiência e formação: do médico ao professor de medicina. Estudo sobre a disciplina formação didáticopedagógica em saúde nos cursos de pós-graduação da Unifesp/EPM. 1997. Tese (Livre Docência) - Universidade Federal de São Paulo, São Paulo, 1997.

BATISTA, N. A.; RIBEIRO, E. C. O. Docência médica profissionalizada. In: PICCINI, R. X. et al. Preparando a Transformação da Educação Médica Brasileira. Pelotas: Universidade Federal de Pelotas, 2000.

BATISTA, S. H. S. S. Lendo Cartas. Aprendendo sobre a docência em medicina. Revista Brasileira de Educação Médica, Rio de Janeiro, v. 26, supl. 1, maio/ago., 2002.

BRASIL. Conselho Federal de Educação. Parecer n 576/70. PósGraduação em Medicina. Documenta 117. Rio de Janeiro, 1970, p. 225-236.

. Conselho Federal de Educação. Resolução $n^{\circ}$ 11/77. Normas para o credenciamento de curso de pós-graduação em Medicina. Documenta 199. Rio de Janeiro, 1977, p. 391-400.

Lei $n^{\circ}$ 9.394, de 20 de dezembro de 1996. Estabelece as Diretrizes e Bases da Educação Nacional. Diário Oficial da União, Brasília, 23 dez. 1996. Seção 1, p. 27833. 
FEUERWERKER, L. C. M. Mudanças na educação médica e residência médica no Brasil. São Paulo: HUCITEC, 1998.

FREITAS, M. A. O.; SEIFFERT, O. M. L. B. Formação docente e o ensino de Pós-Graduação em Saúde: uma experiência na Unifesp. Revista Brasileira de Enfermagem, v. 60, n. 6, p. 635-640, 2007.

GRESSLER, L. A. Introdução à pesquisa: projetos e relatórios. São Paulo: Loyola, 2003.

HAIR, J. F. et al. Análise Multivariada de Dados. 5. ed. São Paulo: Bookman Editora, 2005.

MINAYO, M. C. S. O desafio do conhecimento: pesquisa qualitativa em saúde. São Paulo: HUCITEC, 2004.

NÓVOA, A. Professores, imagens do futuro presente. Lisboa: Educa, 2009.

PEREIRA, J. C. R. Análise de Dados Qualitativos: estratégias metodológicas para ciências da saúde, humanas e sociais. 3. ed. São Paulo: EDUSP/ FAPESP, 2004

ROLDÃO, M. C. Função docente: natureza e construção do conhecimento profissional. Revista Brasileira de Educação, Portugal, v. 12, n. 34, 2007.

RUIZ-MORENO, L.; PITTAMIGLIO, S.; FURUSATO, M. Lista de discussão como estratégia de ensino-aprendizagem na pós-graduação em Saúde. Interface [on-line], Botucatu, v. 12, n. 27, p. 883-892, 2008.

RUIZ-MORENO, L.; SONZOGNO, C.; BATISTA, S. H. S. S.; BATISTA, N. Mapa conceitual: ensaiando critérios de análise. Ciência e Educação (Unesp), v. 13, n. 3, 2007.

RUIZ-MORENO, L.; SONZOGNO, M. C. Formação pedagógica na pósgraduação em saúde no ambiente Moodle: um compromisso social. Pro-Posições (Unicamp. Impresso), Campinas, v. 22, n. 3, set/dez, 2011. 
SEIFFERT, O. M. L. B.; BATISTA, N. A. A experiência vivenciada: analisando e aprendendo mudanças. In: BATISTA, N. A.; BATISTA S. H.; ABDALLA. I. G. (Org.). Ensino em saúde: visitando conceitos e práticas. 1. ed. São Paulo: Arte \& Ciência, 2005. v. 1, p. 335-349.

SARAMAGO, J. Ensaio sobre a cegueira. 12. ed. São Paulo: Companhia das Letras, 1995.

TARDIF, M. Saberes profissionais dos professores e conhecimentos universitários: Elementos para uma epistemologia da prática profissional dos professores e suas consequências em relação à formação para o magistério. Revista Brasileira de Educação, n. 13, 2000.

ZABALZA, M. A. O ensino universitário: seu cenário e seus protagonistas. Porto Alegre: Artmed, 2004. 